\title{
Effect of Carbon Nanofiber Structure on Crystallization Kinetics of Polypropylene/Carbon Nanofiber Composites
}

\author{
Sungho Lee, ${ }^{*}$ Jae Ryang Hahn, ${ }^{\dagger}$ Bon-Cheol Ku, and Junkyung Kim \\ Institute of Advanced Composites Materials, Korea Institute of Science and Technology, Jeollabuk-do 565-902, Korea \\ *E-mail: sunghol@kist.re.kr \\ ${ }^{\dagger}$ Department of Chemistry and Research Institute of Physics and Chemistry, Chonbuk National University, Jeonju 561-756, Korea \\ Received January 17, 2011, Accepted May 31, 2011
}

\begin{abstract}
Effect of heat treatment of carbon nanofibers (CNF) on electrical properties and crystallization behavior of polypropylene was reported. Two types of CNFs (untreated and heat treated at $2300^{\circ} \mathrm{C}$ ) were incorporated into polypropylene (PP) using intensive mixing. A significant drop in volume resistivity was observed with composites containing untreated $5 \mathrm{wt} \%$ and heat treated $3 \mathrm{wt} \% \mathrm{CNF}$. In non-isothermal crystallization studies, both untreated and heat treated CNFs acted as nucleating agents. Composites with heat treated CNFs showed a higher crystallization temperature than composites with untreated CNFs did. TEM results of CNF revealed that an irregular structure of CNFs can be converted into the continuous graphitic structure after heat treatment. Furthermore, STM showed that the higher carbonization temperature leads to the higher graphite degree which presents the larger carbon network size, suggesting that a more graphitic structure of CNFs led to a higher crystallization temperature of PP.
\end{abstract}

Key Words : Polypropylene, Carbon nanofibers, DSC, TEM, STM

\section{Introduction}

Carbon nanofibers (CNFs) based nanocomposites are electrically conductive since CNFs possess a high electrical conductivity. $^{1-7}$ This characteristic is required to be used as housing materials of electric devices to protect them from electromagnetic interference (EMI) and electrostatic discharge (ESD) phenomena. ${ }^{6,7}$ Compared to conventional carbon fiber or carbon black, a less amount of CNFs is needed for composites due to their nano-scale size and high aspect ratio (length over diameter). Furthermore, CNFs have been thermally modified to enhance electrical properties of composites due to an increase of an intrinsic electrical conductivity of CNFs. ${ }^{8,9}$

Graphite is an extremely stable form of carbon. However, CNFs possess defects and irregular structure. When higher temperatures are applied to the $\mathrm{CNFs}$, reorganization occurs to convert them into the more stable graphitic structure. Carbonization and graphitization are essential heat treatment processes of carbonaceous materials. By definition, carbonization implies heat treatment at temperatures of $1700{ }^{\circ} \mathrm{C}$ or less, whereas graphitization refers to heat treatment at temperature $>1700{ }^{\circ} \mathrm{C} .{ }^{10}$ During heat treatment, topological changes of CNFs have been observed. ${ }^{8}$ Endo et al. reported that the formation of energetically stable loops between adjacent graphene layers from unstable edge planes in both the outer surface and the inner hollow core. ${ }^{9}$

Most studies on CNF based nanocomposites have addressed on improving electrical and mechanical properties. ${ }^{1-7,11-14}$ However, it is important to study the effect of temperature and nano-reinforcement on the crystalline structural changes of polymer matrix to process nanocomposites into products.
Lozano et al. observed that in the isothermal crystallization study, $5 \mathrm{wt} \% \mathrm{CNF}$ led to higher nucleation rate of polypropylene (PP), which was reflected with an increase in crystallization temperature by $8{ }^{\circ} \mathrm{C} .{ }^{15}$ Sui et al. prepared PP/ $\mathrm{CNF}$ composites using a twin screw extruder, and their nonisothermal crystallization study showed an increase of crystallization temperature by $18{ }^{\circ} \mathrm{C}$ with an addition of 5 wt $\%$ CNF. ${ }^{16}$ However, there was no significant effect of CNFs on melting temperature and the degree of crystallinity. ${ }^{16}$

In this paper, the effect of heat treatment of CNFs on crystallization behavior of polypropylene (PP) was studied. Two different CNFs were incorporated into PP: untreated $\mathrm{CNF}$ and heat treated $\mathrm{CNF}$ at $2300{ }^{\circ} \mathrm{C}$. Volume resistivity of nanocomposites was measured for their electrical properties. Furthermore, nonisothermal crystallization kinetics of $\mathrm{CNF}$ / PP nanocomposites was investigated by differential scanning calorimetry (DSC). Structure of CNFs was observed using X-ray diffraction (XRD), transmission electron microscopy (TEM), and scanning tunneling microscopy (STM).

\section{Experimental}

Materials. Homo PP (J-150) used in this study was supplied by Honam Petrochem Co. The properties given by the suppliers are the following; density $0.9 \mathrm{~g} / \mathrm{cm}^{3}$, melt flow index (MFI) $10 \mathrm{~g} / 10 \mathrm{~min}$. CNFs, PR-24-XT-PS, were supplied by Applied Science Inc. (Cedarville, USA). These CNFs were prepared from the chemical decomposition of natural gas over Fe-sulfide catalyst at $1100{ }^{\circ} \mathrm{C} .{ }^{17}$ Diameter and length of CNFs were found to be $116 \pm 46 \mathrm{~nm}$ and 1-50 $\mu \mathrm{m}$, respectively. To modify CNFs, heat treatment was ap- 
plied under He atmosphere using a furnace (Cheil-kikun Co., Korea). After CNF loading, the temperature was increased to $2300{ }^{\circ} \mathrm{C}$ at a rate of $5{ }^{\circ} \mathrm{C} / \mathrm{min}$ and the CNFs were held at $2300^{\circ} \mathrm{C}$ for $1 \mathrm{~h}$. After heat treatment, a significant change in diameter and length was not observed.

Preparation of Nanocomposites. Haake Rheomix 600 (Thermo Scientific, USA) was used for intensive mixing of pure PP and various contents (1-10 wt \%) of both untreated and heat treated CNF composites. $100 \mathrm{~g}$ of physically blended PP and CNFs were fed into the device and mixed for $6 \mathrm{~min}$ at $190^{\circ} \mathrm{C}$ under $\mathrm{N}_{2}$ atmosphere. Next, the compounded forms of pure PP (control) and nanocomposites were placed on a heating press (Daeheung Science Co., Korea) at $190{ }^{\circ} \mathrm{C}$. Before compacting, 5 min preheating time was allowed to soften the materials. $2.8 \mathrm{MPa}$ of pressure was applied for $5 \mathrm{~min}$. Subsequently $5.5 \mathrm{MPa}$ of pressure was applied for $3 \mathrm{~min}$, and pressed samples were air-cooled ( $\sim 10$ min) down to ambient conditions.

Characterization. X-ray diffractometer (XRD, Rigaku $\mathrm{D} / \mathrm{Max} 2500 \mathrm{H}$, Japan) of $\mathrm{Cu} \mathrm{K \alpha}$ radiation $(\lambda=1.5406 \AA)$ was used for observing crystalline structure of CNFs over the $2 \theta$ range of 10 to $50^{\circ}$. From XRD, interlayer spacing were calculated. Transmission electron microscope (TEM, JEM2200FS, USA) was used to investigate structure of CNFs. CNFs were dispersed in a vial with acetone and sonicated for $10 \mathrm{~min}$. This solution was dropped on a formvar/carbon film supported carbon grid and dried. In order to characterize the CNFs on the atomic scale with a scanning tunneling microscope, they were deposited on a clean highly-oriented pyrolytic graphite (HOPG) surface (Advanced Ceramics, grade ZYA). By depositing several drops of CNF/acetone solution on a basal plane, welldispersed CNFs on the surface were obtained. The STM images of each CNF were taken using a commercial STM (SOLVER P-47, NT-MDT). Spatial sensitivity of STM piezoelectric tube was calibrated with HOPG and Au (111) crystals. Tips were mechanically cut from a $0.25 \mathrm{~mm}$ wire of $\mathrm{Pt} / \mathrm{Ir}$. The constant current mode (topographical imaging) was employed for investigating the static properties of each CNF. All the images shown are raw data with mean plane subtraction.

The surface electrical resistivity was measured by a digital ohmmeter (Megaohmmeter ACL 800 ) at $\sim 25^{\circ} \mathrm{C}$. The electrical measurements were conducted at two different voltages $(10$ and $100 \mathrm{~V})$ to account for low and high resistances and corrected for specimen geometry to convert surface resistivity to volume resistivity. Measurements were conducted at ten different locations on three replicates. Thermal analysis was performed in a differential scanning calorimeter (DSC Q20, TA instruments, USA). Samples were heated up to $190^{\circ} \mathrm{C}$ at a rate of $10^{\circ} \mathrm{C} / \mathrm{min}$ and held at that temperature for $10 \mathrm{~min}$ to erase thermal history of samples. Subsequently, samples were cooled down to $50{ }^{\circ} \mathrm{C}$ at a rate of $5,10,15$, and $20^{\circ} \mathrm{C} / \mathrm{min}$ and then heated up to $190^{\circ} \mathrm{C}$ again at a rate of $10^{\circ} \mathrm{C} / \mathrm{min}$ for studying the effect of CNFs on the nonisothermal crystallization.

Scanning electron microscope (SEM, Hitachi FE S-4800,
Japan) was used for observing cross-section of nanocomposites. Specimens were cryo-fractured in liquid nitrogen. The specimens were coated with platinum for 1 min using a sputter coater, and then the cross-section was examined. TEM (TECNAI G2, USA) was used to investigate the dispersion of CNFs in composites. After cryo-microtoming at $-50{ }^{\circ} \mathrm{C}$, samples were dispensed on a formvar/carbon film-supported carbon grid.

\section{Results and Discussion}

Characterization of CNFs. Figure 1 showed the integrated azimuthal profiles ( $2 \theta$ scans) from XRD of CNFs. At $2 \theta \approx 26^{\circ}$, a distinct peak associated with the $(002)$ graphene planes appeared for both CNFs. Also, a weak peak and a shoulder were observed at $2 \theta \approx 43$ and $44^{\circ}$, indicating (100) and (101) graphene planes, respectively. It is evident that the intensity of these peaks was higher for heat treated CNFs. Based on these profiles, the interlayer spacing $\left(d_{002}\right)$ was calculated using Bragg's law (0.3400 and $0.3386 \mathrm{~nm}$ for untreated and heat treated CNFs, respectively). As expected, the integrated azimuthal profiles and $\mathrm{d}_{002}$ data confirm that the heat treatment led to a significant increase of graphitic content. Furthermore, it is evident in Figure 2 that continuous crystallites were observed with heat treated CNFs by TEM.

Figures 3(a) and (b) represent the STM topographical images obtained from untreated CNF. In the large scale image, the rod-like structures were observed. It appears that they are aggregated and slightly bent. When the imaging area is highly magnified over a rod, it is difficult to find an area of very symmetric trigonal pattern representing the ideal surface structure of graphite, which can be observed easily on surface of HOPG. This indicates that hexagonal carbon ring is not well defined on this surface. STM image reflects the charge density of surface atoms. Therefore these diverse corrugation patterns can be interpreted as the results of local structural damage such as point, line and dislocation defects.

However, in the STM images obtained from heat treated

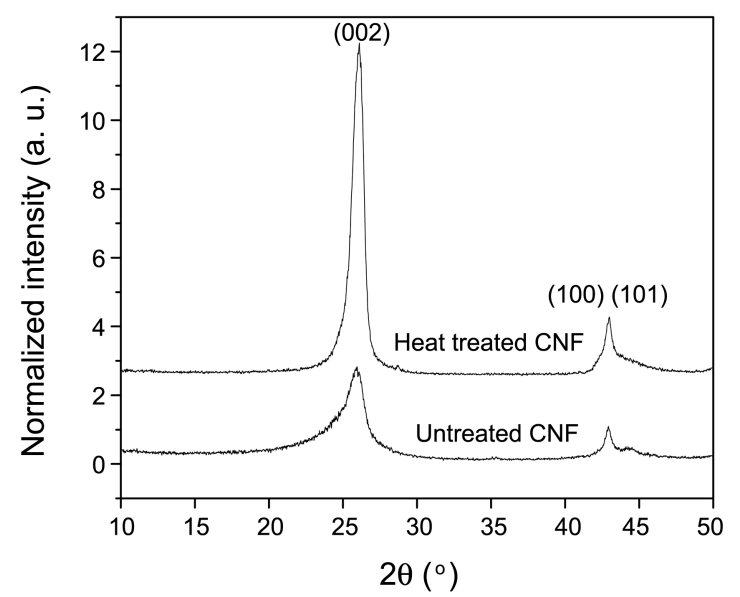

Figure 1. Integrated azimuthal profiles ( $2 \theta$ plots) for untreated and heat treated CNFs. 

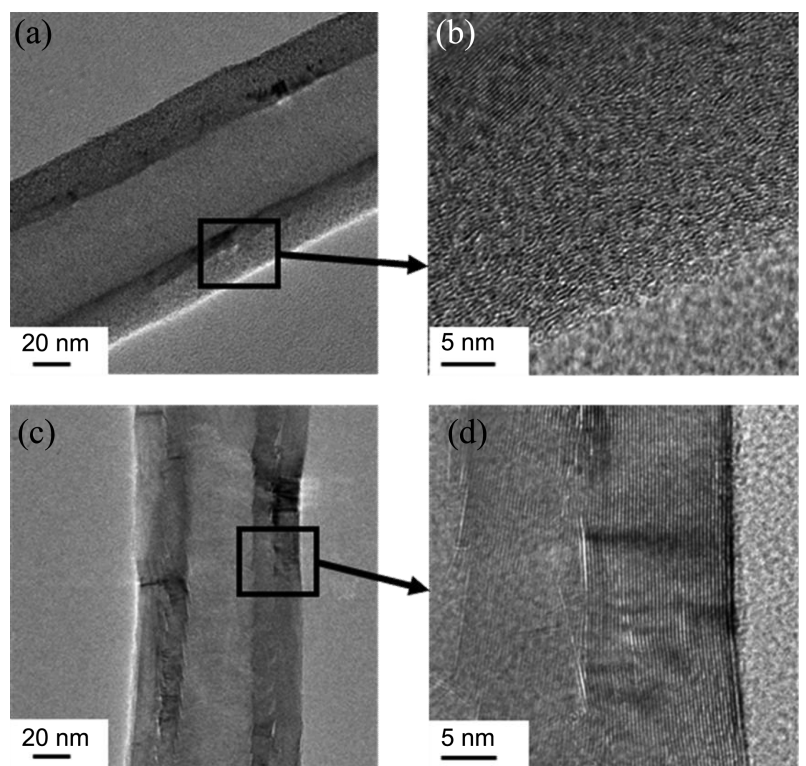

Figure 2. Transmission electron micrographs (TEM) of (a) untreated and (c) heat treated CNFs. (b) and (d) are in high resolution for (a) and (c), respectively.
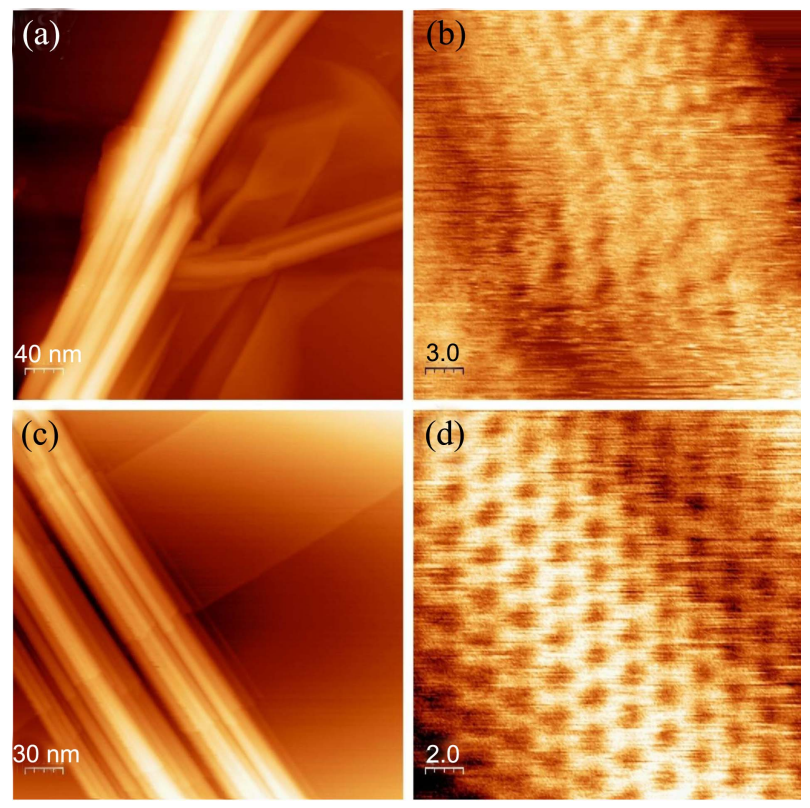

Figure 3. Topographical images of scanning tunneling microscope (STM) for (a) untreated and (c) heat treated CNFs. (b) and (d) are in high resolution for (a) and (c), respectively. The scan area is $400 \times 400,3 \times 3,300 \times 300$, and $2 \times 2 \mathrm{~nm}^{2}$ for images (a), (b), (c), and (d), respectively. They are obtained at tunneling current of 10 pA-2 nA and tip-bias voltage of $20-100 \mathrm{mV}$.

CNFs (Figures 3(c) and (d)) remarkably different structures were observed. In the large-scale image, the well-defined rod-like features were uniformly observed on the nanometer scale with a little bending. At higher resolution image (Figure 3(d)), well-defined carbon surface structures were found. The peak-to-peak (or trough-to-trough) spacing of atomic corrugation was measured to be $0.252 \mathrm{~nm}$, which is very close to that of HOPG. The surface plane appears

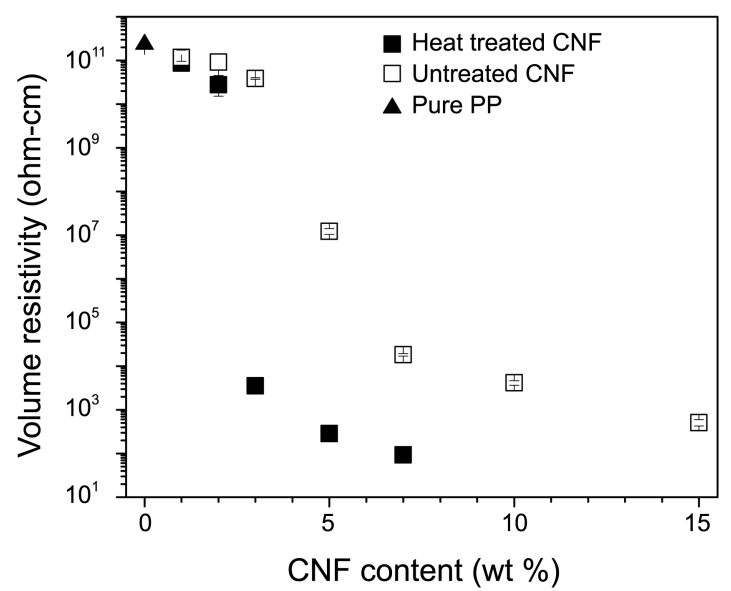

Figure 4. Volume resistivity of pure PP and its composites as function of CNF content.

deformed slightly but the perfect trigonal pattern is maintained. It was reported that the heat-treatment temperatures affected structure formation of carbon nanofiber. ${ }^{9}$ The higher carbonization temperature leads to the higher graphite degree which presents larger carbon network size. This welldefined atomic structure over several tens of nanometer scale was observed.

Electrical Property of Composites. Figure 4 displays volume resistivity of composites containing untreated and heat treated CNFs as a function of CNF content. For untreated $\mathrm{CNF}$ composites, volume resistivity did not change up to $3 \mathrm{wt} \% \mathrm{CNF}$ content. However, a significant drop in volume resistivity was observed at $5 \mathrm{wt} \% \mathrm{CNF}$ composites. A further decrease was found with increase of CNF content, and volume resistivity was $\sim 10^{4} \Omega$-cm with composites containing $10 \mathrm{wt} \% \mathrm{CNFs}$. For heat treated CNFs, a significant drop in volume resistivity $\left(\sim 10^{4} \Omega\right.$-cm) was observed even at $3 \mathrm{wt} \%$, which is seven orders of magnitude drop compared to pure PP. Therefore, electrical percolation threshold of untreated and heat treated CNF composites are at 7 and $3 \mathrm{wt} \%$, respectively, indicating that much more untreated CNFs were needed to make composites conductive.

Dispersion of nanometer scale modifiers in polymer matrices remains a significant issue because a strong van der Waals bonding between nanofillers leads to agglomeration and hinders their dispersion. This agglomeration may reduce the effect of CNFs on electrical conductivity of composites. To investigate this dependency of electrical volume resistivity on CNF type, dispersion of CNFs in PP was examined using SEM and TEM micrographs. After specimens were cryo-fractured in liquid nitrogen with nanocomposites containing $15 \mathrm{wt} \% \mathrm{CNFs}$, SEM was performed to observe dispersion of CNFs. From Figures 5(a) and (b), it is evident that CNFs are well dispersed in all composites. TEM micrographs also showed well dispersed CNFs (Figures 6(a) and (b)). Thus, dispersion issue can be ruled out as the major reason for different volume resistivities of different composites. As expected, this results from an increase of 

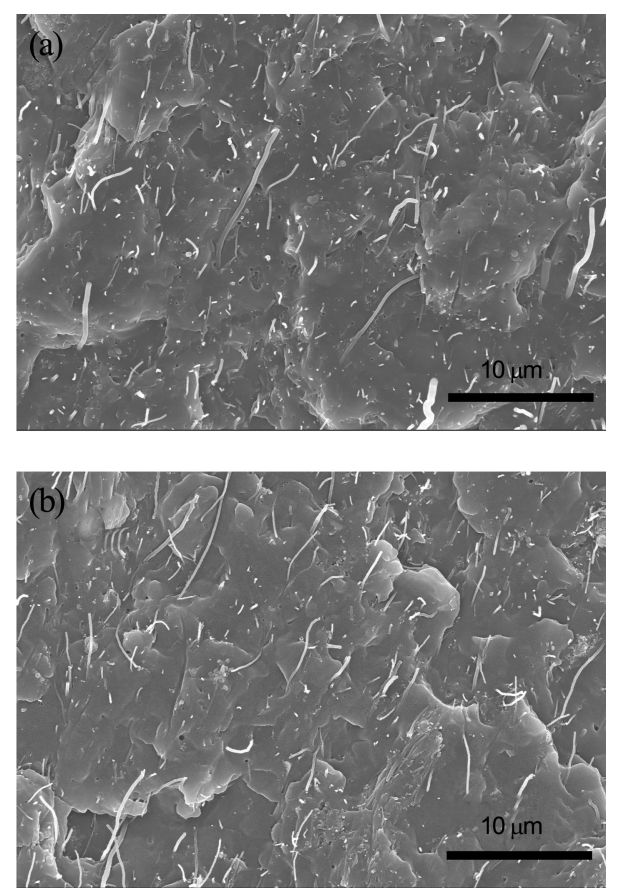

Figure 5. Scanning electron microscope (SEM) micrographs of (a) untreated and (b) heat treated CNF composites.
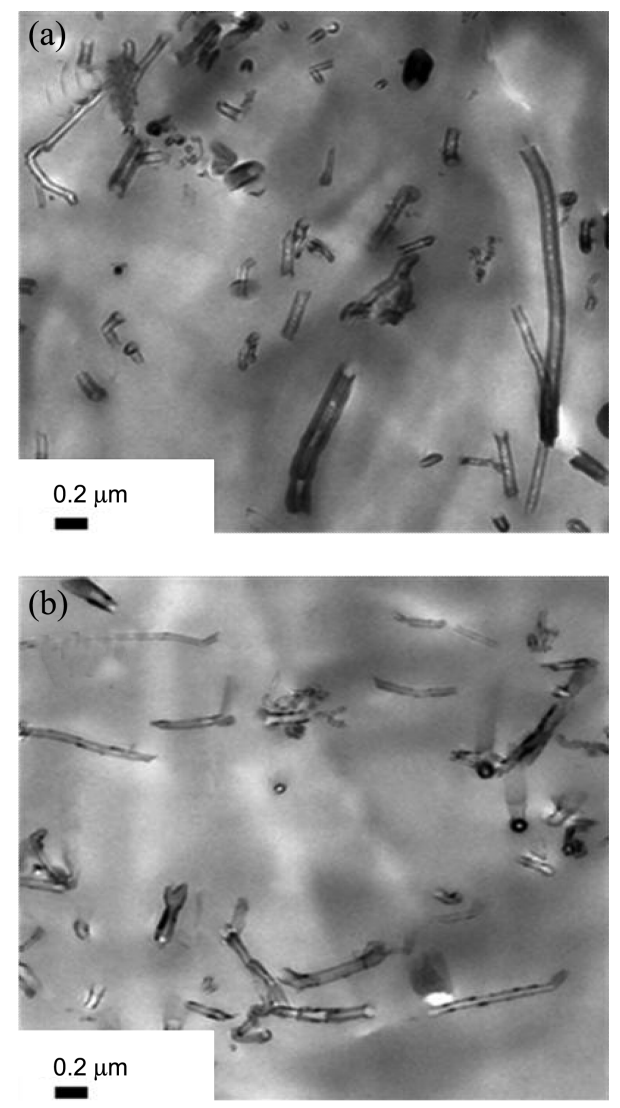

Figure 6. Transmission electron microscope (TEM) micrographs of (a) untreated and (b) heat treated CNF composites.

intrinsic conductivity of CNFs due to heat treatment. It has been reported that heat treatment led to higher order of graphitic structure of carbonaceous materials, which resulted

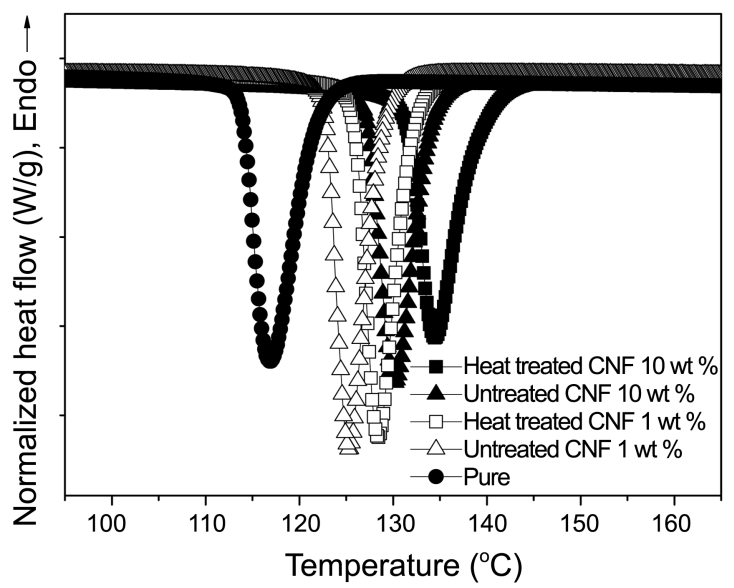

Figure 7. DSC cooling thermograms of pure $\mathrm{PP}$ and its composites at a cooling rate of $5^{\circ} \mathrm{C} / \mathrm{min}$.

in enhancing their electrical conductivity. ${ }^{9}$

Nonisothermal Crystallization Kinetics of Composites. The crystallization behavior of composites with the addition of CNFs was investigated using non-isothermal DSC. For 1 wt $\%$ untreated and heat treated $\mathrm{CNF}$ composites with a cooling rate of $5{ }^{\circ} \mathrm{C} / \mathrm{min}, T_{c}$ was 125.3 and $128.5^{\circ} \mathrm{C}$, respectively, whereas $T_{c}$ of pure PP was $118.5^{\circ} \mathrm{C}$ (Figure 7). Table 1 summarizes crystallization temperatures $\left(T_{c}\right)$, melting temperatures $\left(T_{m}\right)$, and heat of fusion $\left(\Delta H_{m}\right)$ of pure PP and its composites as a function of CNF content (1, 5, and 10 wt $\%$ ) at various cooling rates $\left(5,10,15\right.$, and $\left.20^{\circ} \mathrm{C} / \mathrm{min}\right)$. It is evident that addition of CNFs led to a significant increase in $T_{c}$ with a higher content of CNFs. These suggest a role of $\mathrm{CNFs}$ as nucleating agents. It is interesting to note that heat treated $\mathrm{CNF}$ composites showed a higher $T_{c}$ than untreated $\mathrm{CNF}$ composites did. An addition of CNFs revealed an insignificant change of $T_{m}: 164.9,165.3$, and $166.5^{\circ} \mathrm{C}$ for pure $\mathrm{PP}$, untreated $1 \mathrm{wt} \% \mathrm{CNF}$ composites, and heat treated $1 \mathrm{wt} \% \mathrm{CNF}$ composites, respectively. With a higher CNF content at a given cooling rate, an insignificant change of $T_{m}$ was observed.

Nonisothermal crystallization kinetics of pure PP and its composites were analyzed. The relative degree of crystallinity, $X$, at crystallization time $t$ can be obtained by the following equation:

$$
X=\frac{\int_{T_{o}}^{T}\left(\frac{d H_{c}}{d T}\right) d T}{\int_{T_{o}}^{T_{e}}\left(\frac{d H_{c}}{d T}\right) d T}
$$

where $T_{o}$ and $T_{e}$ are the onset and end crystallization temperatures, respectively, and $d H_{c} / d T$ is the heat flow rate. In nonisothermal crystallization, the time $t$ is related with the temperature $T$ as follows ${ }^{18,19}$ :

$$
t=\frac{T_{o}-T}{\phi}
$$

where $T$ is the temperature at time $t, T_{o}$ is temperature at which the crystallization begins $(t=0)$ and $\phi$ is the cooling 
Table 1. Transition temperatures and heat of fusion of pure PP and its composites at various cooling rates $\left(5,10,15\right.$, and $\left.20{ }^{\circ} \mathrm{C} / \mathrm{min}\right)$ and a constant heating rate $\left(10^{\circ} \mathrm{C} / \mathrm{min}\right)$

\begin{tabular}{|c|c|c|c|c|c|c|c|c|c|c|c|c|}
\hline \multirow{2}{*}{ Sample } & \multicolumn{3}{|c|}{ Cooling rate $\left(5^{\circ} \mathrm{C} / \mathrm{min}\right)$} & \multicolumn{3}{|c|}{ Cooling rate $\left(10^{\circ} \mathrm{C} / \mathrm{min}\right)$} & \multicolumn{3}{|c|}{ Cooling rate $\left(15^{\circ} \mathrm{C} / \mathrm{min}\right)$} & \multicolumn{3}{|c|}{ Cooling rate $\left(20^{\circ} \mathrm{C} / \mathrm{min}\right)$} \\
\hline & $T_{c}\left({ }^{\circ} \mathrm{C}\right)$ & $T_{m}\left({ }^{\circ} \mathrm{C}\right)$ & $\Delta H_{f}\left(\mathrm{~J} / \mathrm{g}_{\mathrm{pp}}\right)$ & $T_{c}\left({ }^{\circ} \mathrm{C}\right)$ & $T_{m}\left({ }^{\circ} \mathrm{C}\right)$ & $\Delta H_{f}\left(\mathrm{~J} / \mathrm{g}_{\mathrm{pp}}\right)$ & $T_{c}\left({ }^{\circ} \mathrm{C}\right)$ & $T_{m}\left({ }^{\circ} \mathrm{C}\right)$ & $\Delta H_{f}\left(\mathrm{~J} / \mathrm{g}_{\mathrm{pp}}\right)$ & $T_{c}\left({ }^{\circ} \mathrm{C}\right)$ & $T_{m}\left({ }^{\circ} \mathrm{C}\right)$ & $\Delta H_{f}\left(\mathrm{~J} / \mathrm{g}_{\mathrm{pp}}\right)$ \\
\hline Pure PP & 118.5 & 164.9 & 92.8 & 113.9 & 163.9 & 93.5 & 110.9 & 163.5 & 92.7 & 108.4 & 163.0 & 92.1 \\
\hline $\begin{array}{l}\text { PP/untreated } \\
\text { CNF } 1 \text { wt } \%\end{array}$ & 125.3 & 165.3 & 93.2 & 121.6 & 164.3 & 91.2 & 119.1 & 163.8 & 91.0 & 117.3 & 163.5 & 90.5 \\
\hline $\begin{array}{l}\mathrm{PP} / \text { untreated } \\
\mathrm{CNF} 5 \mathrm{wt} \%\end{array}$ & 127.7 & 165.5 & 92.1 & 124.0 & 164.7 & 90.1 & 121.8 & 164.3 & 90.6 & 120.0 & 164.0 & 88.5 \\
\hline $\begin{array}{l}\mathrm{PP} / \text { untreated } \\
\mathrm{CNF} 10 \mathrm{wt} \%\end{array}$ & 130.2 & 165.5 & 89.9 & 126.7 & 164.6 & 88.6 & 124.3 & 164.4 & 87.3 & 122.6 & 163.9 & 86.9 \\
\hline $\begin{array}{l}\mathrm{PP} / \text { treated } \\
\text { CNF } 1 \mathrm{wt} \%\end{array}$ & 128.5 & 166.5 & 92.3 & 124.5 & 165.6 & 93.6 & 122.1 & 165.1 & 92.1 & 120.0 & 164.6 & 91.5 \\
\hline $\begin{array}{l}\mathrm{PP} / \text { treated } \\
\mathrm{CNF} 5 \mathrm{wt} \%\end{array}$ & 132.3 & 167.0 & 92.8 & 128.7 & 166.3 & 92.2 & 126.2 & 165.8 & 90.8 & 124.5 & 165.6 & 90.5 \\
\hline $\begin{array}{l}\text { PP/treated } \\
\text { CNF } 10 \mathrm{wt} \%\end{array}$ & 134.5 & 166.5 & 91.7 & 130.5 & 165.0 & 91.1 & 128.3 & 164.8 & 86.2 & 127.0 & 163.9 & 84.9 \\
\hline
\end{tabular}

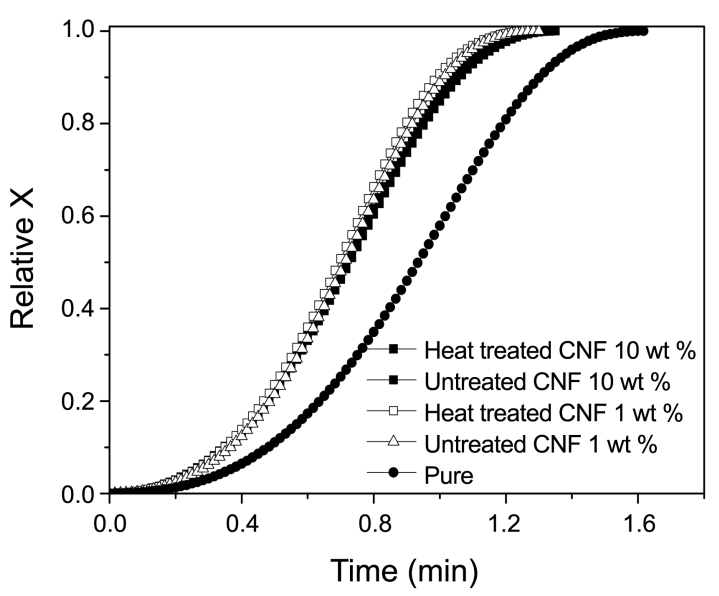

Figure 8. Relative crystallinity with time for nonisothermal crystallization of pure $\mathrm{PP}$ and its composites at a cooling rate of $5^{\circ} \mathrm{C} / \mathrm{min}$. rate. Using above two equations, $X$ vs $t$ plots of pure PP and its composites containing $1 \mathrm{wt} \% \mathrm{CNFs}$ are shown at a cooling rate of $5^{\circ} \mathrm{C} / \mathrm{min}$ (Figure 8 ). Half-crystallization time $\left(t_{1 / 2}\right)$ calculated from $X$ vs $t$ plots such as Figure 8 was summarized in Table 2 at various cooling rates and CNF contents. It was apparent that the higher CNF content and the lower cooling rate needed less time to reach the given relative degree of crystallinity, indicating a faster crystallization. However, there was an insignificant difference in $t_{1 / 2}$ between untreated CNF composites and heat treated CNF composites. From these results, it is noteworthy that similar crystallization rates of untreated $\mathrm{CNF}$ composites were revealed to those of heat treated $\mathrm{CNF}$ composites.

Avrami equation has been used for isothermal crystallization kinetics of polymers. ${ }^{20}$ With the simplified assumption that crystallization occurs under constant temperature,

Table 2. Avrami crystallization exponent $(n)$, rate constant $\left(Z_{c}\right)$, and half-time of crystallization $\left(t_{1 / 2}\right)$ of pure PP and its composites at various cooling rates $\left(5,10,15\right.$, and $\left.20^{\circ} \mathrm{C} / \mathrm{min}\right)$ and a constant heating rate $\left(10^{\circ} \mathrm{C} / \mathrm{min}\right)$

\begin{tabular}{|c|c|c|c|c|c|c|c|c|c|c|c|c|}
\hline \multirow{2}{*}{ Sample } & \multicolumn{3}{|c|}{ Cooling rate $\left(5^{\circ} \mathrm{C} / \mathrm{min}\right)$} & \multicolumn{3}{|c|}{ Cooling rate $\left(10^{\circ} \mathrm{C} / \mathrm{min}\right)$} & \multicolumn{3}{|c|}{ Cooling rate $\left(15^{\circ} \mathrm{C} / \mathrm{min}\right)$} & \multicolumn{3}{|c|}{ Cooling rate $\left(20^{\circ} \mathrm{C} / \mathrm{min}\right)$} \\
\hline & $n$ & $Z_{c}$ & $t_{1 / 2}(\min )$ & $n$ & $Z_{c}$ & $t_{1 / 2}(\min )$ & $n$ & $Z_{c}$ & $t_{1 / 2}(\min )$ & $n$ & $Z_{c}$ & $t_{1 / 2}(\min )$ \\
\hline Pure PP & 2.7 & 1.0 & 0.94 & 2.7 & 1.1 & 0.52 & 2.8 & 1.1 & 0.42 & 2.8 & 1.1 & 0.31 \\
\hline $\begin{array}{l}\text { PP/untreated } \\
\text { CNF } 1 \text { wt \% }\end{array}$ & 2.7 & 1.1 & 0.71 & 2.8 & 1.1 & 0.40 & 2.9 & 1.1 & 0.30 & 2.9 & 1.1 & 0.23 \\
\hline $\begin{array}{l}\text { PP/untreated } \\
\text { CNF } 5 \text { wt \% }\end{array}$ & 2.7 & 1.1 & 0.72 & 2.8 & 1.1 & 0.41 & 2.8 & 1.1 & 0.30 & 2.9 & 1.1 & 0.23 \\
\hline $\begin{array}{l}\text { PP/untreated } \\
\text { CNF } 10 \text { wt } \%\end{array}$ & 2.6 & 1.1 & 0.73 & 2.7 & 1.1 & 0.37 & 2.8 & 1.1 & 0.28 & 2.8 & 1.1 & 0.22 \\
\hline $\begin{array}{l}\mathrm{PP} / \text { treated } \\
\text { CNF } 1 \mathrm{wt} \%\end{array}$ & 2.7 & 1.1 & 0.70 & 2.8 & 1.1 & 0.41 & 2.8 & 1.1 & 0.28 & 2.8 & 1.1 & 0.23 \\
\hline $\begin{array}{l}\mathrm{PP} / \text { treated } \\
\text { CNF } 5 \text { wt \% }\end{array}$ & 2.6 & 1.1 & 0.72 & 2.7 & 1.1 & 0.38 & 2.9 & 1.1 & 0.28 & 2.9 & 1.1 & 0.22 \\
\hline $\begin{array}{l}\mathrm{PP} / \text { treated } \\
\text { CNF } 10 \mathrm{wt} \%\end{array}$ & 2.6 & 1.1 & 0.72 & 2.7 & 1.1 & 0.40 & 2.75 & 1.1 & 0.27 & 2.8 & 1.1 & 0.22 \\
\hline
\end{tabular}


the nonisothermal crystallization kinetics of polymer and polymer nanocomposites was studied by Avrami equation as follows ${ }^{21,22}$ :

$$
1-X(t)=\exp \left(-Z_{t} t^{n}\right)
$$

or

$$
\log [-\ln (1-X(t))]=n \log t+\log Z_{t}
$$

where $n$ is the Avrami crystallization exponent dependent on the mechanism of nucleation and $Z_{t}$ is a crystallization rate constant. These two constants as kinetic parameters are associated with crystalline morphology and type of nucleation at a particular crystallization condition. It was proposed that a crystallization rate constant should be modified to consider the influence of cooling rate in nonisothermal crystallization and is determined as a crystallization rate constant as follows ${ }^{23}$ :

$$
\log Z_{c}=\frac{\log Z_{t}}{\phi}
$$

In case Avrami equation is adequate for nonisothermal crystallization, the plots of $\log [-\ln (1-X(t))]$ against $\log t$ give a straight line, and the intercept and the slope of the lines is associated with kinetic parameters $Z_{c}$ and $n$, respectively, summarized in Table 2. The Avrami plots of a pure PP and its composites are shown at a cooling rate of $5{ }^{\circ} \mathrm{C} / \mathrm{min}$ in Figure 9. It has been reported that $n$ values of pure PP were between 2 and 3, attributed to heterogeneous nucleation followed by spherulitic crystalline growth. ${ }^{24}$ In our study, $n$ values lied in 2.6 to 2.9 for all samples, which is consistent with other PP composite systems such as PP/carbon nanotubes, ${ }^{25} \mathrm{PP} /$ nano-calcium carbonate, ${ }^{26}$ and PP/clay composites. $^{27}$ They increased with an increase of cooling rate. However, at a given cooling rate and CNF content, $n$ values of both untreated and heat treated CNF composites showed similar to those of pure PP. Therefore, Avrami crystallization analysis suggests that although incorporation of CNFs led to higher crystallization rate, nucleation mechanism and morphology of PP were not changed significantly. In addi-

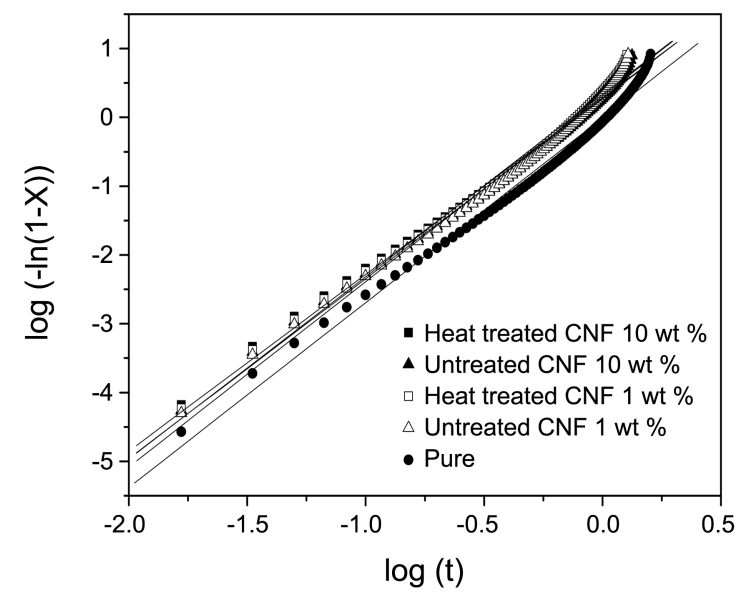

Figure 9. Plots of $\log [-\ln (1-X(t))]$ versus $\log t$ for nonisothermal crystallization of pure PP and its composites at a cooling rate of 5 ${ }^{\circ} \mathrm{C} / \mathrm{min}$.

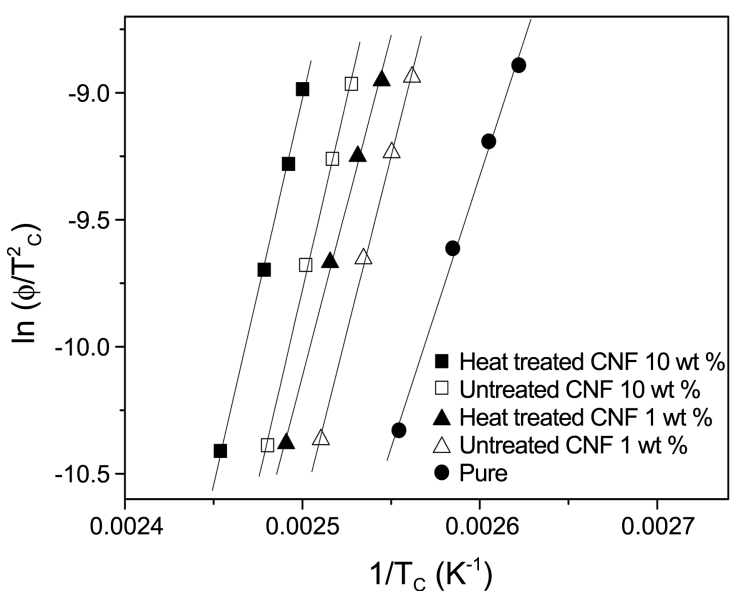

Figure 10. Plots of $\ln \left(\phi / T_{c}^{2}\right)$ versus $1 / T_{c}$ for nonisothermal crystallization of pure PP and its composites at a cooling rate of 5 ${ }^{\circ} \mathrm{C} / \mathrm{min}$.

tion, both untreated and heat treated CNFs revealed a similar effect on crystallization rate of PP.

Using nonisothermal cooling scans, the activation energy and the activity of the nucleation in our system were calculated. Kissinger reported that the activation energy for the transport of the macromolecular segments to the growing surface can be obtained by calculating the variation of $T_{c}$ with the cooling rate $\phi .^{28}$

$$
\frac{d\left[\ln \left(\phi / T_{c}^{2}\right)\right]}{d\left(1 / T_{c}\right)}=\frac{-\Delta E}{R}
$$

where $R$ is the gas constant. Activation energy is obtained by a straight line in the plot of $\ln \left(\phi / T_{c}^{2}\right)$ vs $1 / T_{c}$. Figure 10 represents these plots for pure $\mathrm{PP}$ and both untreated and heat treated $\mathrm{CNF}$ composites at $\mathrm{CNF}$ contents of 1 and 10 wt $\%$. An increase of CNF content led to higher $\Delta E$ values, indicating that motion of polymer chain slugged by increase of melt viscosity of composites (Table 3). However, $\Delta E$ values were not different between untreated and heat treated CNF composites.

The nucleating activity of the filler was calculated by Dobreva. ${ }^{29,30}$ In the case of study of the nonisothermal crystallization process, the following relationships were proposed:

Table 3. Activation energy and nucleation activity of pure PP and its composites

\begin{tabular}{lcc}
\hline Sample & $\begin{array}{c}\text { Activation } \\
\text { energy } \\
(\Delta E, \mathrm{~kJ} / \mathrm{mol})\end{array}$ & $\begin{array}{c}\text { Nucleation } \\
\text { activity } \\
(\varepsilon)\end{array}$ \\
\hline Pure PP & 178 & 1 \\
\hline PP/untreated CNF 1 wt \% & 231 & 0.83 \\
PP/untreated CNF 5 wt \% & 245 & 0.71 \\
PP/untreated CNF 10 wt \% & 250 & 0.60 \\
\hline PP/heat treated CNF 1 wt \% & 223 & 0.68 \\
PP/ heat treated CNF 5 wt \% & 246 & 0.54 \\
PP/ heat treated CNF 10 wt \% & 253 & 0.49 \\
\hline
\end{tabular}




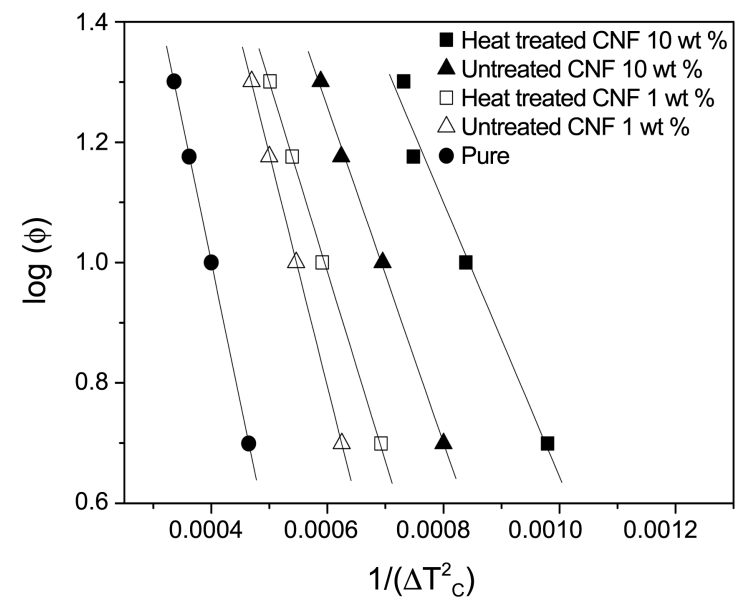

Figure 11. Plots of $\log \phi$ versus $1 / \Delta T_{c}^{2}$ for nonisothermal crystallization of pure PP and its composites at a cooling rate of $5{ }^{\circ} \mathrm{C} / \mathrm{min}$.

$$
\log \phi \approx \text { const }-\frac{B}{2.3 \Delta T_{c}^{2}}
$$

where $\Delta T_{c}$ is equal to $T_{m}-T_{c}$ ( $T_{m}$ is the melting temperature). $B$ is a parameter which can be calculated from following equation:

$$
B=\omega \frac{\sigma^{3} V_{m}^{2}}{3 k T_{m} \Delta S_{m}^{2} n}
$$

where $V_{m}$ is the molar volume of the crystallizing polymer, $\Delta S_{m}$ is the entropy of melting, $k$ is the Boltzmann constant, $\sigma$ is the specific surface energy and $\omega$ is a geometrical factor.

The activity of the nucleation of the filler, $\varepsilon$, is defined as the ratio between the three-dimensional work of nucleation with and without filler ( $A_{f}$ and $A_{0}$, respectively). If the filler is extremely active for nucleation, $\varepsilon$ approaches 0 . And for absolutely inert particles $\varepsilon$ is 1 . Furthermore, the threedimensional work of nucleation $A$ is equal to $n T_{m} B$, where $n$ is the Avrami exponent. Since the value of $n$ stays nearly constant, as shown in the previous Avrami analysis, the following relationship holds:

$$
\varepsilon=\frac{A_{f}}{A_{o}}=\frac{B_{f}}{B_{o}}
$$

Therefore, the nucleation activity can be directly given by the ratio between the slopes of the linear curves of $\log \phi v s$. $1 / \Delta T_{c}^{2}$ with filler and without filler (Figure 11). As expected, lower $\varepsilon$ values were observed with composite compared to pure PP, and a more addition of CNFs led to lower $\varepsilon$ values (Table 3). Furthermore, lower $\varepsilon$ values of heat treated $\mathrm{CNF}$ composites than untreated CNF composites suggest that heat treated CNFs are more effective nucleation agents.

Polymer crystalline structure was produced by nucleation and growth. It is likely that heat treated CNFs are the more effective nucleation agent. However, after the nucleation, untreated and heat treated CNFs composites did not show a significantly different effect on the polymer growth mechanism, because surfacial morphology of CNFs plays a major role on only the nucleation of polymer. Therefore, overall crystallinity, crystallization rates, and Avrami kinetics parameters can be similar.

Li et al. reported that transcrystallization of polyethylene (PE) prepared by physical vapor deposition on CNTs in nanocomposites, called the soft epitaxial growth, depended on surface roughness and wall structure of CNTs. ${ }^{31}$ They claimed that rough surface and chemical groups of CNTs can hinder crystallization of PE on CNTs. Therefore, a uniform and smooth graphene-like structure of CNTs is preferred for the soft epitaxial growth. ${ }^{31}$ In our study, the higher graphitic structure of CNTs led to the higher crystallization temperature and the lower nucleation activity value of PP. This suggests that CNTs with the highly ordered graphitic structure play significant nucleating agents due to the more effective epitaxial growth of PP.

\section{Conclusions}

A significant drop in volume resistivity started with composites with 5 and $3 \mathrm{wt} \%$ of untreated and heat treated $\mathrm{CNF}$ content due to a decrease of intrinsic volume resistivity of CNFs after heat treatment. Non-isothermal DSC analysis of composites indicated that an addition of CNFs led to increase of $T_{c}$ significantly and higher $T_{c}$ was observed with higher content of CNFs, suggesting a role of CNFs as nucleating agents. For $1 \mathrm{wt} \%$ untreated and heat treated composites with a cooling rate of $5^{\circ} \mathrm{C} / \mathrm{min}, T_{c}$ were 125.3 and $128.5^{\circ} \mathrm{C}$, respectively, whereas $T_{c}$ of pure PP was 118.5 ${ }^{\circ} \mathrm{C}$. Furthermore, nucleating activity results revealed that heat treated CNFs are more effective nucleation agents, resulting in a higher $T_{c}$ with composites containing heat treated CNFs. However, overall crystallinity, crystallization rates, and Avrami kinetics parameters of untreated CNF composites were not significantly different from these of heat treated CNF composites, indicating that CNFs do not affect the growth of polymer crystalline structure significantly. TEM results of carbon nanofiber revealed that an irregular structure of carbon nanofibers was converted into the continuous graphitic structure after heat treatment. STM showed that the higher carbonization temperature leads to the higher graphite degree which presents larger carbon network size. This morphological difference of CNFs contributed to a higher crystallization temperature of heat treated CNF composites than that of untreated CNF composites.

Acknowledgments. This work was supported by a grant from Korea Institute of Science and Technology Institutional program and the Fundamental R\&D Program for Core Technology of Materials funded by the Ministry of Knowledge Economy, Republic of Korea (2M26840). JRH was supported by the National Research Foundation of Korea (NRF) grant funded by the MEST (2010-0001638).

\section{References}

1. Lozano, K.; Bonilla-Rios, J.; Barrera, E. V. J. Appl. Polym. Sci. 2001, 80, 1162 . 
2. Kuriger, R. J.; Alam, M. K.; Anderson, D. P.; Jacobsen, R. L. Composites Part A 2002, 33, 53.

3. Hammel, E.; Tang, X.; Trampert, M.; Schmitt, T.; Mauthner, K.; Eder, A.; Potschke, P. Carbon 2004, 42, 1153.

4. Hine, P.; Broome, V.; Ward, I. Polymer 2005, 46, 10936.

5. Howe, J. Y.; Tibbetts, G. G.; Kwang, C.; Lake, M. L. J. Mater. Res. 2006, 21,2646

6. Lee, B. O.; Woo, W. J.; Kim, M. S. Macromol. Mater. Eng. 2001, 286, 114.

7. Yang, S.; Lozano, K.; Lomeli, A.; Foltz, H. D.; Jones, R. Composites Part A 2005, 36, 691.

8. Kim, Y. A.; Matusita, T.; Hayashi, T.; Endo, M.; Dresselhaus, M. S. Carbon 2001, 39, 1747

9. Endo, M.; Kim, Y. A.; Hayashi, T.; Yanagisawa, T.; Muramatsu, H.; Ezaka, M.; Terrones, H.; Terrones, M.; Dresselhaus, M. S. Carbon 2003, 41, 1941.

10. Buckley, J. D.; Edie, D. D. NASA Reference Publication 1254; U.S.A., 1992; p 22.

11. Kumar, S.; Doshi, H.; Srinivasarao, M.; Park, J. O.; Schiraldi, D. A. Polymer 2002, 43, 1701.

12. Kuriger, R. J.; Alam, M. K.; Anderson, D. P. J. Mater. Res. 2001, $16,226$.

13. Ma, H.; Zeng, J.; Realff, M. L. Compos. Sci. Technol. 2003, 63, 1617.

14. Zeng, J.; Saltysiak, B.; Johnson, W. S.; Schiraldi, D. A.; Kumar, S. Composites Part B 2004, 35, 245.
15. Lozano, K.; Barrera, E. V. J. Appl. Polym. Sci. 2001, 79, 125.

16. Sui, G.; Zhong, W. H.; Fuqua, M. A.; Ulven, C. A. Macromol. Chem. Phys. 2007, 208, 1928.

17. Tibbetts, G. G.; Lake, M. L.; Strong, K. L.; Rice, B. P. Compos. Sci. Technol. 2007, 67, 1709.

18. Cebe, P. Polym. Compos. 1988, 9, 271.

19. Herrero, C. R.; Acosta, J. L. Polym. J. 1994, $26,78$.

20. Avrami, M. J. Chem. Phys. 1939, 7, 1103.

21. Nakamura, K.; Watanabe, T.; Katayama, K.; Amano, T. J. Appl. Polym. Sci. 1972, 17, 1077.

22. Nakamura, K.; Katayama, K.; Amano, T. J. Appl. Polym. Sci. 1973, 17, 1033.

23. Jeziorny, A. Polymer 1978, 19, 1142.

24. Sperling, L. H. Introduction to Physical Polymer Science, 3rd ed.; John Wiley \& Sons, Inc.: New York, U.S.A., 2001; Chap. 6.

25. Valentini, L.; Biagiotti, J.; Lopez-Manchado, M. A.; Santucci, S.; Kenny, J. M. Poly. Eng. Sci. 2004, 44, 303.

26. Zhu, W.; Zhang, G.; Yu, J.; Dai, G. J. Appl. Polym. Sci. 2004, 91 , 431.

27. Li, J.; Zhou, C.; Gang, W. Polym. Test. 2003, 22, 217.

28. Kissinger, H. E. J. Res. Natl. Bur. Stand. 1956, 57, 217.

29. Dobreva, A.; Gutzow, I. J. Non-crystalline Solids 1993, 162, 1.

30. Dobreva, A.; Gutzow, I. J. Non-crystalline Solids 1993, 162, 13.

31. Li, L.; Yang, Y.; Yang, G.; Chen, X.; Hsiao, B. S.; Chu, B.; Spanier, J. E.; Li, C. Y. Nano Letters 2006, 6, 1007. 